\title{
Os passeios da Rua Barão de lguape: disputas na implementação dos equipamentos viários em São Paulo no fim do século XIX
}

The sidewalks of Barão de lguape street: disputes in the implementation of road equipment in São Paulo at the end of the $19^{\text {th }}$ century

http://dx.doi.org/10.1590/1982-02672019v27e04

\section{MONIQUE FÉLIX BORIN'}

https:/ / orcid.org/0000-0002-8374-937X

Universidade de Campinas / Campinas, SP, Brasil

RESUMO: Este artigo explora a relação entre o poder público e a população de São Paulo na implementação dos equipamentos viários no período entre 1886 e 1905, analisando seu impacto sobre o fazer urbano da cidade. A partir do estudo de caso de intimações para que moradores da rua Barão de lguape, localizada no bairro central da Liberdade, construíssem os passeios em frente a suas edificações no ano de 1904, discutimos como eram entendidas as responsabilidades sobre a organização urbana naquele momento histórico. Para isso, abordaremos os conflitos e negociações, expressos na documentação das Obras particulares do acervo do Arquivo Histórico de São Paulo. A opção de trabalhar com um elemento de infraestrutura em geral negligenciado, tido como menor em comparação aos outros melhoramentos em implementação - característica que também se expressa na documentação - base da reflexão -, visa justamente apreender a relação entre esses atores no nível do cotidiano. Somos confrontados com um tipo de relação entre esses agentes bastante recorrente na cidade desde o período colonial: um compartilhamento da ação do poder público e dos moradores para a feitura da cidade. $\bigcirc$ calçamento das ruas da cidade e a construção de seus passeios é um dos exemplos de como essa relação se materializava na paisagem urbana, complexificando as dimensões das disputas políticas envolvidas na urbanização paulistana no fim do século XIX.

PALAVRAS-CHAVE: Passeio. Urbanização. Melhoramentos. São Paulo. Liberdade (bairro). Obras particulares (fonte).
1. Doutoranda em história na Universidade Estadual de Campinas (Unicamp) e pesquisadora do Centro Interdisciplinar de Estudos sobre a Cidade (Ciec). Possui mestrado em história social pela Universidade de São Paulo (USP) e bacharelado e licenciatura em história pela Pontifícia Universidade Católica de São Paulo. Bolsista Fapesp. E-mail: <moniquebfelix@ gmail.com>. 
ABSTRACT: This article explores the relation between public authority and the population of São Paulo in the implementation of road equipment in the period between 1886 and 1905, analyzing how it impact on the "urban making" of this city. Based in a case study of summonses to residents of Barão de lguape street, located in the central neighborhood of Liberdade, to construct the sidewalks in front of their buildings in 1904, we discussed how were understood the responsibilities on the urban organization in that historical moment. For this, we will approach their conflicts and negotiations, expressed in the documentation of the "Obras particulares", of the Historical Archive of São Paulo. The option of working with a generally neglected element of infrastructure, which is considered minor in comparison with the other improvements that were being implemented, characteristic that is also expressed in the central documentation of this article, is precisely to apprehend the relationship between these actors at the level of daily life. We are confronted with a kind of relationship between these agents that was quite recurrent in the city since the colonial period: a sharing of the action of the public authority and of the inhabitants for the making of the city. The pavement of the city's streets and the construction of the sidewalks is one of the examples of how this relationship materialized in the urban landscape, making complex the dimensions of the political disputes involved in the urbanization of São Paulo in the late nineteenth century.

KEYWORDS: Sidewalk. Urbanization. Improvements. São Paulo. Liberdade (neighborhood). Obras particulares (source). 
Em 1904, Manuel Francisco Duarte, proprietário do imóvel localizado na rua Barão de Iguape $n^{\circ} 88$, foi intimado pela Prefeitura Municipal de São Paulo para construir um passeio em frente de sua propriedade. ${ }^{2}$ Naquele ano e no seguinte, pelo menos doze intimações foram realizadas aos proprietários e moradores de construções localizadas nessa rua, com o prazo de dez dias para a realização das obras, especificando a necessidade de "calçar com pedras de cantaria lavada ou outro qualquer sistema de concreto na largura marcada pelo nivelamento das guias a frente dos prédios". ${ }^{3}$ Tantas intimações em um mesmo ano indicam que a instalação das guias para delimitar a largura e o nivelamento dos passeios havia sido recém-realizada pela Prefeitura. Esta reforma viária não estava restrita ao passeio: na sequência de sua intimação, Manuel solicita o prolongamento do prazo para a construção do calçamento, pois o terreno recebeu um grande aterro e não estaria firme o suficiente para tal intervenção. $\bigcirc$ responsável do imóvel pediu o prazo de noventa dias, concedido pela municipalidade e cumprido pelo solicitante, o qual termina a obra no prazo estendido que recebeu. $\bigcirc$ aterro da rua parece ter sido realmente expressivo, tendo gerado outras solicitações - como a de Vicente Cazzi, que pede para alterar o muro do imóvel no 111 , já "que tendo essa digna Prefeitura mandado atersrar a rua ficou o muro muito baixo, querendo agora o suplicante levantar um metro na extensão de 18,80 vem por meio deste pedir a necessaria licença". ${ }^{4}$

A rua Barão de lguape se localiza na Liberdade, um dos bairros centrais de São Paulo, na direção sul a partir da Sé, sendo uma das diversas ladeiras dessa região que ligavam o planalto em que se iniciou o núcleo urbano paulistano à várzea do rio Tamanduateí. ${ }^{5}$ É uma das ruas que representam bem o terreno

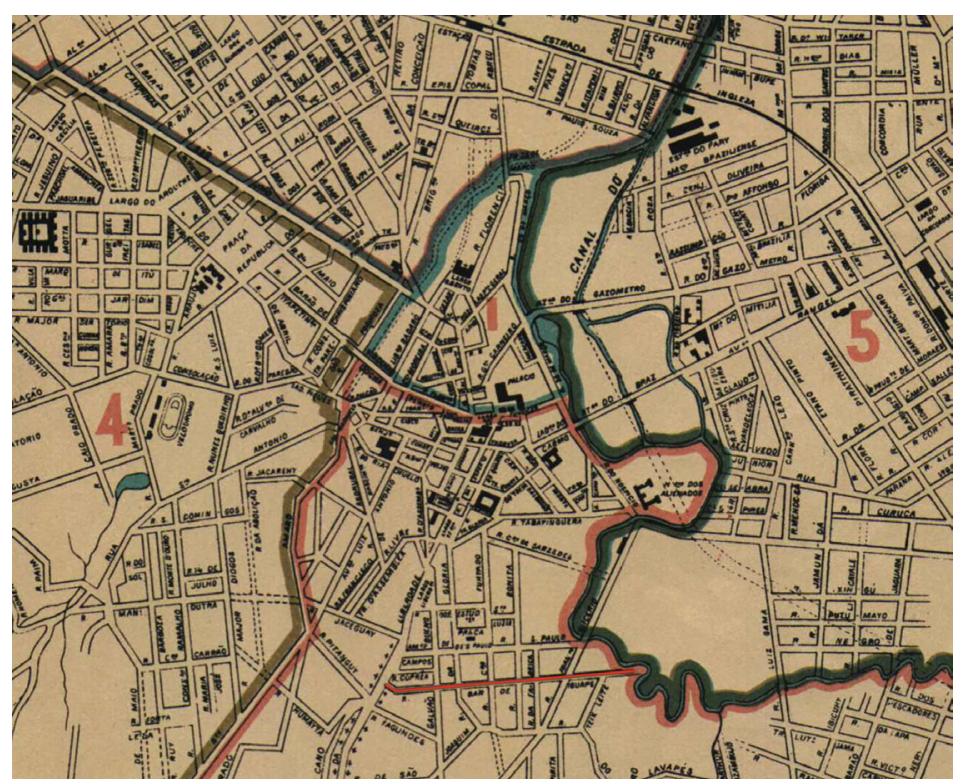

Figura 1 - Recorte da Planta Geral da Capital de São Paulo, 1897. A rua Barão de lguape está destacada em vermelho, mostrando que acabava diretamente no rio antes da retificação. Fonte: Comissão do IV Centenário da Cidade de São Paulo. São Paulo antigo: plantas da cidade. São Paulo, Companhia Me|horamentos, $1954 .^{\circ}$
2. Arquivo Histórico de São Paulo (1916). Intimação a Manuel Francisco Duarte. Rua Barão de Iguape, $\mathrm{n}^{\circ} 88$. Encadernado 376. Série Obras Particulares. Subfundo Diretoria de Obras e Viação. Fundo Prefeitura Municipal de São Paulo.

3. Nas citações diretas da documentação, optamos por manter a grafia original.

4. Arquivo Histórico de São Paulo (1916). Intimação a Vicente Cazzi. Rua Barão de Iguape, $\mathrm{n}^{\circ} 111$. Encadernado 376.

5. O Triângulo Histórico de São Paulo, delimitado pelas ruas São Bento, Direita e XV de novembro (antiga rua da Imperatriz), concentrava a São Paulo urbana nos períodos colonial e imperial, e é hoje conhecido como "centro velho" da cidade. Localiza-se em um planalto, sobre as várzeas dos rios Tamanduateí e Anhangabaú.

6. Nesse recorte da Planta Geral de 1897 localizamos o bairro da Liberdade ao sul do Triângulo Histórico, assim como a rua Barão de Iguape em relação ao traçado do rio Tamanduateí. A opção pelas duas plantas aqui apresentadas faz parte da abordagem mais geral de nossa pesquisa de doutorado em curso, em que tanto a Planta Geral da Capital de São Paulo (1897) quanto a Planta da Cidade de São Paulo (1924), mostrando todos os arrabaldes e terrenos arruados, são entendidas como ferramentas na construção da imagem de espraiamento da cidade a partir das opções políticas realizadas nas relações entre poder público e agentes dos negócios urbanos, como discutido por Kuvasney (2016) e Simoni (2009). Não nos propomos, portanto, a fazer aqui um estudo focado nessas fontes, mas é importante destacar a 
relação destas com as disputas do fazer urbano no momento em questão, assim não as mobilizamos de maneira casual ou ilustrativa, mas sim que são parte intrínseca de nossa reflexão mais ampla sobre a urbanização paulistana nesse momento histórico ainda que nos furtemos aqui de aclarar todas as relações por opção de não nos afastar da documentação que é centro de análise neste artigo.

\section{Cf. Lesser (2007).}

8. Esse é um processo bastante complexo, que tem relação com as formas de reprodução do capital pelo fazer urbano, mas também com as estratégias de domínio e controle políticosocial pelas reformas $\mathrm{e}$ intervenções urbanas, que abriria outro eixo de análise para além do que nos propomos neste artigo. Podemos ver nas disputas pela urbanização da Várzea do Carmo, do rio Tamanduateí, um caso em que os interesses de lucro imediato com a exploração do terreno liberado pelo saneamento da área a partir de seu loteamento e da construção de casas de aluguel para os setores médios foi preterida em relação à construção de um parque, que condizia mais com a perspectivas da separação da cidade valorizada com as terras além-Tamanduateí - que, na prática, eram parte importante do mercado de terras urbanas, imobiliário e rentista, mas que em uma condição de desprestígio integrava uma condição ideológica que permeava o mercado de negócios urbanos por essa diferenciação das zonas da cidade. Processos mais explícitos e menos refinados podem ser vistos nas transformações da várzea do entorno do rio Pinheiros, onde cheias foram acidentado do bairro, expressando uma morfologia elemento importante no tipo de ocupação desse território - que por sua vez é bastante remota na história da cidade, abrigando equipamentos urbanos importantes desde o século XVIII.

Quando o primeiro cemitério público da cidade, que se localizava no coração do bairro da Liberdade, é desativado em 1858, ocorre a ocupação mais densa da região a partir do loteamento de suas terras. ${ }^{7}$ A relação do bairro com a várzea do Tamanduateí foi uma constante nas estratégias de implementação dos equipamentos de infraestrutura nesse território, relacionando-se tanto às práticas de sociabilidade de seus habitantes quanto às estratégias do mercado de terras urbanas. A várzea inundável desse rio era bastante expressiva antes de suas sucessivas retificações, gerando um território que tinha múltiplos usos para a população da cidade nos períodos colonial e imperial. Como espaço de busca de sobrevivência, trabalho e lazer, o Tamanduateí estava atrelado ao cotidiano da cidade. As áreas inundáveis eram uma opção barata de moradia para os setores mais pauperizados, e simultaneamente constituíam uma reserva de terras urbanas bem localizadas para o mercado especulativo. Podemos ver nas disputas pela urbanização das várzeas da cidade estratégias de agentes urbanos para buscar reproduzir capital a partir dos processos de retificação e do saneamento de suas áreas alagáveis. Esse é um elemento interessante que permeia o processo em que nos focamos neste artigo, já que naquele momento foram muitas as propostas de agentes que queriam assumir a responsabilidade por essas reformas, tendo como contrapartida a autorização estatal para explorar as terras que fossem liberadas para o mercado urbano por essa intervenção. ${ }^{8}$ É importante destacar as relações entre os administradores públicos e os investidores nos negócios urbanos, que muito frequentemente eram membros das mesmas famílias ou eles próprios investidores - tratamos então, nesse momento histórico, das estratégias do poder público para reformas urbanas, dessa imbricação entre interesses do capital privado e do poder público que são constitutivos desse processo. Apesar das diversas tentativas, as obras de retificação dos rios foram os melhoramentos ${ }^{9}$ urbanos que mais receberam atenção do poder público nesse momento, que em grande parte gestou e encampou com recursos próprios esse tipo de intervenção - destacamos também que esse assunto da retificação e das várzeas era constante em abaixo-assinados de moradores e reclamações em jornais. ${ }^{10}$ As ações para tornar os rios o mais retilíneo possível ecoavam outras investidas na busca de uma regularidade da forma urbana: o nivelamento das ruas - assim como o alinhamento das construções - será uma das principais preocupações do poder público em São Paulo na passagem do século XIX para 
- XX, gerando um impacto expressivo na vida de seus habitantes e na imagem da cidade.

Esse tipo de intervenção urbana, geralmente interpretado como uma série de pequenas reformas cotidianas sem grande alcance e minimizadas nos estudos da urbanização, incidem decisivamente sobre as tendências na morfologia dos bairros, conformando uma materialidade histórica desses territórios, que por vezes é mais duradoura que suas edificações. A perenidade de um tipo de traçado urbano e as pequenas e grandes disputas para se tentar alterá-lo nos permitem explorar as múltiplas camadas e relações dos agentes urbanos desse período em São Paulo, bem como dimensionar a participação da população e seus costumes nas opções que se concretizaram. $\bigcirc$ trajeto da documentação aqui trabalhada é parte constitutiva dessa abordagem: as Obras particulares, uma série documental caracterizada por pedidos de particulares para intervenções em suas propriedades (ou da qual estão usufruindo por diversos motivos), está em geral principalmente vinculada à construção e reforma de edifícios, sendo muito abordada na historiografia por seus croquis e plantas; no entanto há também diversos documentos que tratam da relação dos moradores com - poder público quanto aos limites da relação entre a propriedade e o espaço público. Essa documentação permite uma visão a partir de pequenas escalas de intervenção urbana, guardando diversas outras miudezas, como o caso dos passeios da Barão de lguape. Assim, a própria característica da documentação nos permitiu traçar o caminho inverso do usual, abordando através deste caso pontual aspectos fundamentais dos projetos políticos para a urbanização que estavam em disputa nem sempre muito claros e explicitados.

Neste artigo refletimos sobre as formas de interação entre os moradores e o poder público na implementação da infraestrutura viária em São Paulo, focando nos equipamentos mais cotidianos: ruas, calçadas, vielas. Para isso, mobilizamos a legislação referente a esse tema, as intimações da parte do poder público e as solicitações feitas por moradores e proprietários, explorando a natureza desses melhoramentos e como eles eram lidos pelos diferentes agentes. "1 Tratamos de perscrutar as implicações políticas do aparato envolvido nos melhoramentos urbanos em curso nesse período, refletindo sobre como em processos de diferentes escalas se construiu a legitimação da técnica como um operador neutro nas intervenções urbanas - e como a força ideológica dessa argumentação conseguiu transpor para análises contemporâneas esse entendimento de neutralidade. A largura das ruas, as opções de seu nivelamento, seu calçamento, o tipo da construção de seus passeios e a quem competia cada passo nesses procedimentos são todas questões que nos permitem pensar sobre o tipo de espaço urbano que se estava construindo e sobre as diferentes visões de cidade nos embates desse processo. provocadas intencionalmente pela Light S.A. para se apropriar de mais terras do poder público do que previam acordos iniciais. Assim, a multiplicidade dos agentes envolvidos nesse tipo de especulação com as terras urbanas é bastante emblemática de como o próprio fazer a cidade foi ponto fundamental para o acúmulo de capital que tornou São Paulo o condutor financeiro do país, relacionando-se com as pequenas reformas aqui tratadas. Para disputas sobre a Várzea do Carmo, cf. Oliveira (2005); sobre os processos especulativos em torno do rio Pinheiros, Seabra (1987); sobre a reprodução do capital pela própria reprodução da cidade em São Paulo, Brito (2010).

9. Utilizamos o termo mais corrente na época para esse tipo de intervenção urbana, e destacamos também a palavra por se tratar de um conceito que guarda representações específicas, valorativas, às ações do poder público sobre a cidade. Para uma discussão nessa abordagem, cf. Cerasoli (2004).

10. Cf. Andrade (1991), Enokibara (2003), Oliveira (2005) e Vanessa Ribeiro (2012).

11. Abordamos o termo melhoramento como uma metáfora reiteradamente utilizada pelos agentes urbanizadores de São Paulo, tal como propôs Bresciani (2001, p. 343-344): “A palavra melhoramento e a expressão melhoramentos materiais são presenças constantes nos diferentes enunciados sobre a cidade de São Paulo no decorrer de mais de um século. [...] a palavra melhoramentos, além de ser um lugarcomum, permitindo a troca de opiniões sobre coisas diferentes sempre 
relacionadas com a ideia de um acréscimo positivo àquilo que se refere, também atua como metáfora, ou seja, algo que articula um sentido a uma representação, ou a uma realização mental sob forma de imagem. Consegue assim reunir três dimensões, a do lugar-comum, a conceitual e a figurativa. Provê com imagens, por vezes interligadas, uma opinião e/ ou um conceito".

12. Cf. Dias (1995) e Santos (2013).

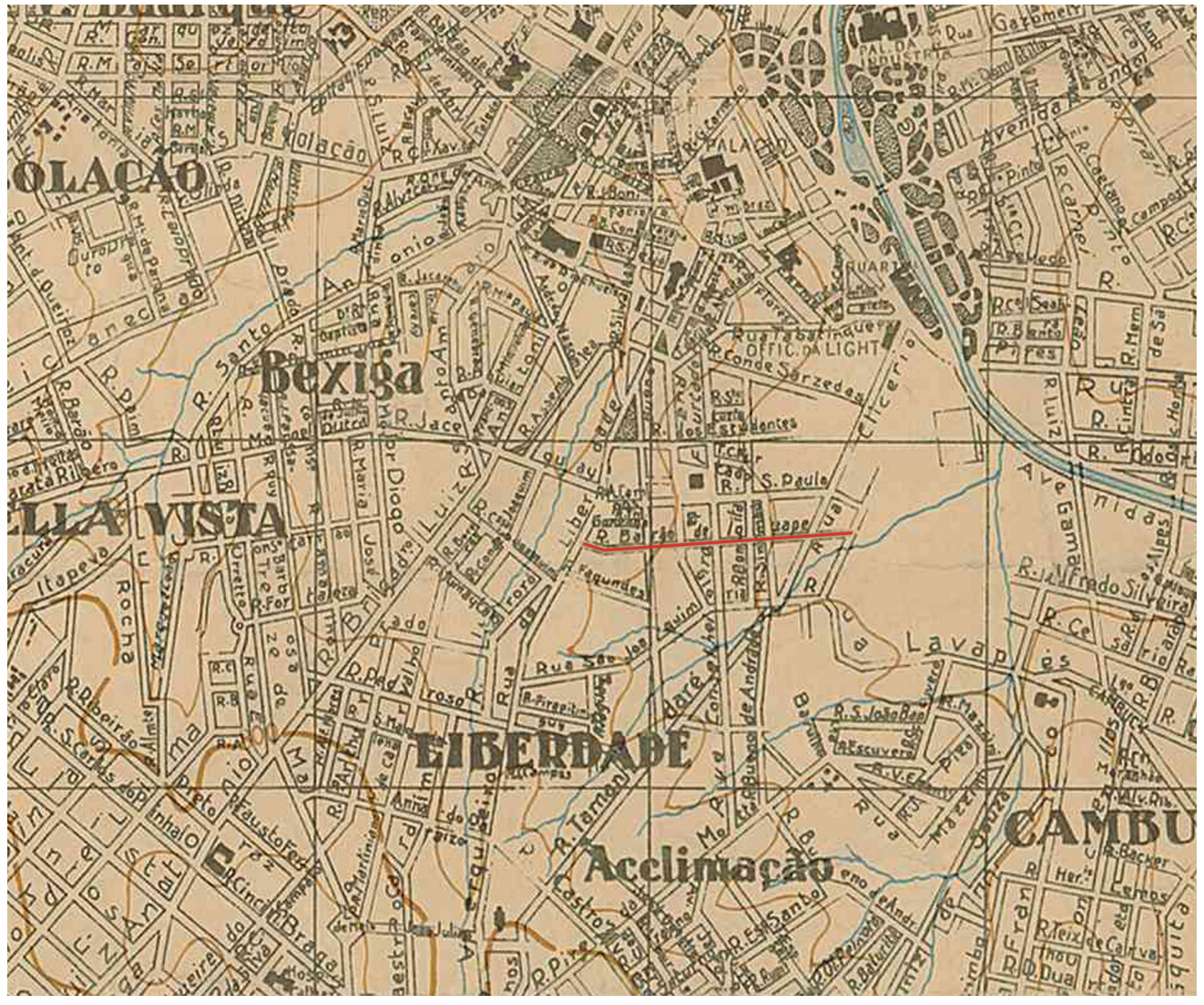

Figura 2 - Recorte da Planta da Cidade de São Paulo, 1924, mostrando todos os arrabaldes e terrenos arruados, e também a rua Barão de lguape, destacada em vermelho, após a retificação do rio Tamanduateí. Fonte: Fundo Instituto Geográfico e Cartográfico (IGC), sob guarda do Arquivo Público do Estado de São Paulo (Apesp).

\section{ARRUAR, NIVELAR, CALÇAR: AS TENDÊNCIAS DA LEGISLAÇÃO PARA OS EQUIPAMENTOS VIÁRIOS}

As intimações recebidas pelos moradores e proprietários da rua Barão de Iguape e as negociações e conflitos que se seguiram têm vínculo com uma série de leis que buscavam regular o uso do espaço urbano. Trataremos diretamente das regulamentações que mais diretamente se relacionam com as intimações aqui analisadas. Apesar dessa abordagem aparentemente pontual, vários dos processos com o quais nos defrontamos são correlatos a outros na relação entre poder público e os moradores desde o período colonial. ${ }^{12}$ Nas notificações enviadas aos moradores, a Prefeitura acionava a Lei n²09, de 11 de março de 1896, que exigia o calçamento dos passeios por parte do proprietário do lote, a partir do 
momento que estes tivessem guias colocadas pela Prefeitura, no prazo de três meses. ${ }^{13}$ Essa lei, no entanto, era apenas um reforço a uma legislação já existente e ainda em vigor: o Padrão Municipal, instituído poucos meses antes do Código de Posturas Municipal e a ele posteriormente incorporado, ambos do ano de 1886. Não são poucos os casos nos estudos de legislações que normativas se sobrepõem, arbitrando sobre assunto semelhantes, seja por imperícia dos legisladores, seja para criar um efeito de necessidade de cumprimento mais rigoroso de determinadas disposições. Nesse caso, as questões envolvidas nesta sobreposição de legislações têm de considerar um dado importante: enquanto o Código de Posturas Municipal é uma legislação imperial, a lei acionada nas intimações pela Prefeitura já é do período republicano.

Código de Posturas Municipal era uma legislação bastante ampla, reunindo em um único documento diversas normativas relacionadas a ocupação, comportamento dos habitantes e manutenção da cidade. Ela trata tanto da ocupação física, determinando regras pera edificações e arruamentos, quanto das normas de convivências para realizações de festejos nas ruas, de funcionamento de estabelecimentos comerciais e de circulação para bondes e carroças, além de conter uma série de medidas dedicadas às questões sanitárias e higiênicas. Nesse sentido, é uma legislação muito mais ampla e abrangente que a Lei n²09, que é curta é só reforça a disposição do artigo $2^{\circ}$ do Padrão Municipal, o qual já previa que:

Todos os proprietários são obrigados a calçar, dentro do prazo de tres mezes, a frente de suas casas, desde que estas tenham sido guarnecidas de guias.

O material a empregar pelos particulares em tal calçamento será unicamente a pedra liza, natural ou artificial, com tanto que apresente as necessárias condições de durabilidade e solidez.

A largura e a declividade dos passeios serão marcados pelo engenheiro da Câmara. ${ }^{14}$

Padrão Municipal segue em vigor até 1920, quando recebe uma nova versão. Na anterior, que integra o Código de Posturas de 1886, o Padrão tem seis tópicos, os quais tratam do alinhamento das construções, do calçamento dos passeios, da abertura de ruas por particulares, de construções e reconstruções, da altura das construções e dimensão de portas, janelas e balcões e, por fim, de cortiços, casas de operários e cubículos. Assim, são disposições voltadas para os moradores da cidade em suas práticas construtivas, em geral de pequeno porte, com uma intervenção mais pontual e localizada. No Código de Posturas vemos normativas para intervenções construtivas mais amplas, que transpõem os limites da
13. São Paulo (Município). Lei $\mathrm{n}^{\circ} 209$, de 11 de março de 1896. Obriga a construção de passeios e fechos de terrenos. São Paulo, Câmara Municipal de São Paulo, 11 mar. 1896. Disponível e m : documentacao.saopaulo. sp.leg.br/iah/fulltext/leis/ L209.pdf. Acesso em: 08 dez. 2018.

14. São Paulo (Município). Padrão Municipal. Anexo ao Código de Posturas do Município de São Paulo. Diário Oficial do Município, São Paulo, 6 out. 1886. Seção 1, p. 8503. 
15. Optamos pelo destaque da palavra modernização por não comportar um significado único, mas por ser um conceito histórico que contém uma série de discussões e conflitos, tanto contemporâneos ao período desta pesquisa quanto na historiografia sobre ele. Essa perspectiva é elaborada mais extensamente no estudo de Cerasoli (2004).

16. Rodrigues (2010, p. 52).

17. Cf. Bruno (1954) e Santos (2013).

18. Santos (Op. cit., p. 96).

19. Ibidem, p. 97. propriedade individual. A abertura de ruas por particulares passa a ter um padrão, determinando a largura de $16 \mathrm{~m}$, e definindo a forma quadrada para praças e largos "tanto quanto o terreno permitir", que só poderiam ser realizadas a partir de então, após o pedido de alinhamento e nivelamento à câmara, "sob pena de multa de 30 \$, além de ser obrigado à demolição das obras". Esse tipo de direcionamento e fiscalização elaborado pelo engenheiro da Câmara e fixado pelo Código de Posturas foi tratado como um dado fundamental para dimensionar as formas de modernização ${ }^{15}$ de São Paulo por parte da historiografia.

Entendido como uma novidade nas normativas, o aval do engenheiro estabeleceria assim um início, uma gênese para a implementação posterior de um planejamento urbano mais efetivo. Podemos ver um exemplo desse tipo de abordagem na formulação de Gustavo Rodrigues, em seu estudo sobre a implementação de vias públicas em São Paulo no primeiro meio século republicano: "um avanço fundamental fora a obrigatoriedade de acompanhamento dessas melhorias por um profissional engenheiro, decretando a passagem das obras empíricas para a era da técnica na construção de vias, praças e infraestruturas". ${ }^{16}$ No entanto, nem a preocupação com a qualidade e regularidade dos calçamentos nem $\circ$ acompanhamento desse tipo de obras por engenheiros parecem ser novidades nas formas de gestão do espaço urbano paulistano.

Estudos sobre as obras públicas na cidade no século XVIII mostram tanto o elogio de viajantes ao calçamento da cidade quanto as constantes estratégias do poder público para realizar o calçamento e a manutenção destes. ${ }^{17}$ Os problemas variavam da escassez de material à dificuldade de conseguir transporte desde as pedreiras até o local das obras, o que gerou a obrigatoriedade de todos os donos de carroças da cidade realizarem um frete mensal para o calçamento das ruas a partir de disposição da Câmara. ${ }^{18}$ A medida foi tomada em 1783, quando o órgão determinou que cada proprietário estaria obrigado a calçar a porção da rua em frente a seu lote com recursos próprios. Os serviços foram coordenados pela Câmara, a partir da presença do engenheiro militar João da Costa Ferreira, e foram iniciados na rua São Bento. A continuidade do calçamento, entretanto, só acontecia após a finalização do serviço anterior, pois não havia condições de transporte de materiais de serviço disponível para serem realizados calçamentos em larga escala concomitantemente. ${ }^{19}$ A realização das obras de calçamento se efetivou, como indicado pela continuação do serviço com a indicação das próximas ruas a serem calçadas pela Câmara, porém não transcorreram sem embates da população com o poder público, gerando diversas ameaças de punição e multas.

As obras foram realizadas pelos trabalhadores costumeiros desse tipo de serviço no Brasil colonial sob a supervisão do engenheiro militar. A descrição das 
etapas de trabalho encontradas na documentação relativa ao calçamento da rua São Bento nos traz um panorama das características dos trabalhadores envolvidos em cada tipo de função:

Os reparos no calçamento podem ser divididos em duas etapas, uma em cada ano. Nas seis semanas de atividades de 1798, todos os serviços foram realizados por negros que tiraram pedras e pelos carreiros que as transportavam, com grande número de repetições. Entre os doze negros participantes das obras, quatro trabalharam em, ao menos, duas semanas, sendo que dois deles estiveram presentes em cinco delas. Os carreiros tiveram um número ainda maior de recorrência: dos nove trabalhadores, apenas dois cumpriram uma única semana. Um terço deles esteve em quatro semanas de trabalho. No ano de 1799, os trabalhos foram menos extensos e envolveram um número consideravelmente menor de pessoas. $O$ pedreiro Marcelino prestou serviço por três dias em janeiro, provavelmente avaliando as condições do calçamento e propondo os reparos necessários. [...] Um grupo de sete presos trabalhou no mesmo ano, mas não há indicação precisa da data - supomos que tenham realizado o transporte do material e executado as obras indicadas pelo pedreiro. ${ }^{20}$

Cotidiano da construção civil em São Paulo seguirá significativamente constituído por trabalhadores sem especialização formal, mesmo após as regulamentações profissionais de engenheiros civis e arquitetos em 1933.21 Parte expressiva das edificações particulares eram pensadas e projetadas por profissionais sem diploma ou educação formal, e o dia a dia dos canteiros das obras públicas, mesmo quando contavam com a determinação de supervisão de engenheiros, mantinham uma dinâmica muito mais ligada aos saberes dos trabalhadores que as tocavam. ${ }^{22} \bigcirc$ trabalho forçado de pessoas que estavam prestando penas criminais e de pessoas negras escravizadas eram fundamentais tanto no trabalho braçal quanto na criação de estratégias que viabilizavam as construções, inclusive nos cenários de precariedade apontados. A dependência desses trabalhadores por parte da construção civil em São Paulo é expressa na valorização da propriedade de pessoas escravizadas com ofícios fundamentais para esse setor. ${ }^{23}$ Tebas, um construtor negro escravizado, responsável pela construção de importantes equipamentos públicos como a antiga lgreja da Sé e reconhecido por sua habilidade em conduzir e encontrar estratégias construtivas mais adequadas para diferentes tipos de obras, é um representante visível na historiografia dessa configuração do cotidiano do trabalho em obras em São Paulo. ${ }^{24}$ A distinção social da formação em engenharia, no período colonial e parte do imperial, contava com outros pressupostos de hierarquia em relação ao restante da força de trabalho no canteiro do que a autoridade da técnica. ${ }^{25}$
20. Ibidem, p. 97.

21. Cf. Novo (2018) e Pareto Júnior (2016).

22. Na designação pejorativa da época, esses profissionais eram conhecidos como "práticos". Essa denominação expressa uma longa disputa por legitimação de atuação nesse campo profissional. Cf. Novo (2018).

23. Cf. Oliveira (2005) e Santos (2013).

24. Cf. Cerqueira (2011) e Wagner Ribeiro (2012).

25. Como apresenta o trabalho de Bueno (2011), a concepção militar da engenharia no período será fundamental para estruturar a distinção social dessa profissão junto às outras carreiras tradicionais - e será intrínseca às concepções sobre o papel do engenheiro na "construção da nação". 
26. Aqui tratamos tanto dos embates da população com o poder público quanto das disputas internas para a formação dos campos disciplinares, como a formação do campo do urbanismo.

27. Sobre as implicações políticas e as formulações ideológicas em torno do conceito da técnica e da figura do engenheiro, cf. Bresciani (2002) e Choay (1965).

28. A criação da Intendência se deu pela Lei Municipal $\mathrm{n}^{\circ} 9$, de 3 de dezembro de 1892, do regimento interno da Câmara Municipal da cidade de São Paulo; já sua transformação em Secretaria se deu pelo Ato $\mathrm{n}^{\circ}$, de 30 de abril de 1894.
A função da figura do engenheiro nas reformas urbanas da segunda metade do século XIX está ligada diretamente à construção de ideologia da neutralidade da técnica, na qual está apoiada o entendimento da presença desses profissionais como "um triunfo da técnica sobre o saber empírico". As conceitualizações do que seria o "saber empírico" e a "técnica" são uma expressão dos fortes embates políticos envolvidos na disputa pelo fazer da cidade nesse momento. ${ }^{26} \mathrm{~A}$ naturalização da figura do engenheiro como um "avanço" nas práticas construtivas em São Paulo abriga a visão da progressividade na implementação das legislações, como se de um período ao outro, de uma lei a outra, os instrumentos de controle do espaço fossem paulatinamente aperfeiçoados. Assim como a técnica não é neutra, atendendo a um largo processo de formulação ideológica constitutivo desse momento histórico, a legislação também atende às diversas disputas concretas entre os agentes urbanos. ${ }^{27}$

Nesse estudo de caso de intimações sobre passeios, em que vemos o reforço da uma norma de período imperial por uma lei no período republicano, se explicita que as negociações e os embates precisavam ser constantemente refeitos e revalidados, quebrando a noção de um caminho contínuo de constante melhoramento da cidade em direção à modernização. É necessário nos atentarmos a isso para abordar a reestruturação administrativa que se seguiu à proclamação da República, já que nesse momento a função pública de manutenção física da cidade passou a um responsável específico com a criação da Intendência de Obras Municipais em 1892. O órgão era responsável tanto pela abertura de ruas e realização de calçamentos de responsabilidade pública quanto por acompanhar obras de particulares e dar-hes o devido alinhamento e nivelamento. Também tinha como arribuição realizar o levantamento da planta cadastral do município, previsto já no Código de Posturas, para tornar possível o papel de fiscalização dos arruamentos da cidade. Apenas dois anos depois, a Intendência é transformada na Secretaria da Obras Municipais. ${ }^{28}$ Esse quadro organizativo é novamente transformado com a criação da figura do Prefeito, em 1898, passando a responsabilidade dessas ações para a Diretoria de Obras. Esse processo aparentemente progressivo e retilíneo da administração de obras é a narrativa criada para enfatizar o triunfo da técnica - desprezando a maleabilidade entre as práticas e as legislações do período imperial e da primeira república.

A institucionalização das esferas públicas responsáveis por, de alguma forma, supervisionar a urbanização, fez parte da construção de um discurso que alegava a necessidade de intensificar as ações de intervenção e controle devido ao crescimento exponencial que a cidade viveu na última década do século XIX. Assim, para dar conta das demandas de implementação dos novos equipamentos 
de infraestrutura, se "necessitava de correção e evolução técnica"29 dos melhoramentos realizados na cidade no período anterior, realizando a "passagem dos processos de embelezamento para os processos de urbanização". 30 Esse verniz impenetrável da técnica norteará as ações da Diretoria de Obras, que tem nos seus primeiros anos de existência ações voltadas principalmente para "pavimentar ruas, implantar bueiros e sarjetas, criar passeios para os pedestres, 'urbanizar' os antigos caminhos de acesso e ligação com os bairros afastados e adequar a deficiente geometria da cidade aos trilhos". ${ }^{31}$ As ações da autoproclamada moderna Diretoria de Obras atualizam, no entanto, preocupações já presentes no imperial Código de Posturas, que demonstra uma premência em conduzir uma padronização e homogeneização da forma urbana na capital paulista. Diversas posturas gravitavam em torno da liberação do espaço da rua para a circulação de pessoas e veículos, assim como nos regramentos republicanos.

As Posturas combinavam preocupações estéticas, sanitárias e viárias, determinando formas de construir que não atrapalhassem o fluxo das calçadas, seja por criar um alinhamento homogêneo, pela obrigação de portas e janelas abrirem para dentro das construções, impedindo a criação de certos tipos de balcões (arts. 11 e 18), ou mesmo regulando as formas de descarte do lixo e das águas advindas das casas (art. 41). Os passeios eram de responsabilidade do proprietário e/ou morador, tanto de seu calçamento quanto de sua conservação e limpeza (art. 39), embora não mais fosse legalmente um espaço de seu arbítrio, já que qualquer elemento que dificultasse a locomoção, como degraus, animais presos a porta e outros tipos de objetos, eram passíveis de multa tanto quanto os demais elementos construtivos. Seis artigos do título IV são dedicados a regular a feitura de buracos para festejos e a proibição de se fazer buracos em terrenos públicos para obtenção de terra, enquanto o título XVIII versa sobre "vagabundos, embusteiros, tiradores de esmolas e rifas", legislando sobre as formas proibidas de se permanecer no espaço público. Outra regulação do uso da rua semelhante é feita no art. 257, que proíbe "os alaridos, vozerias e gritarias pelas ruas. $\bigcirc$ infrator incorrerá na multa de 5 ou 24 horas de prisão". ${ }^{32}$ Há uma larga preocupação com o tráfego de veículos como carroças e bondes, sendo que ao todo são dedicados 27 artigos ao tema, três deles diretamente vinculados a cuidados nas manobras para evitar acidentes, além de diversas disposições sobre normas de conduta de trabalhadores e passageiros nos veículos. A disputa pelos usos da rua, por fazê-la local de circulação ou permanência, atravessa a segunda metade do século XIX em São Paulo, permeando assim questões candentes na historiografia das cidades ocidentais:
29. Rodrigues (2010, p. 85).

30. Ibidem, p. 86 .

31. Ibidem, Loc. cit.

32. São Paulo (Município). Código de Posturas do Município de São Paulo. Diário Oficial do Município, São Paulo, 6 out. 1886. Seção 1, p. 8503. 
33. Frehse (2011, p. 25).

34. Cf. Dias (1994).

35. "Reclamação", $A$ Província de São Paulo, 21 de julho de 1885. In: Frehse (2005, p. 149).

36. O tema da circulação será fundamental para a construção do campo do urbanismo e de sua autoridade técnica nas intervenções urbanas, em todas as dimensões possíveis desse termo. Se na legislação ligada aos equipamentos viários o termo parece se relacionar apenas à locomoção de pessoas e mercadorias, no fundo guarda um vínculo com uma das discussões centrais das reformas urbanas do século XIX, estando estruturalmente imbrincadas, como expõe Bresciani (2014, p. 66): "Em processo simultâneo, se impôs o desamontoar de pessoas em obediência ao princípio de distribuição espacial dos corpos em função da quantidade de suas exalações. A 'higiene física' conjugada a 'higiene social' passava a exigir a aeração do tecido urbano muito denso, para isso contribuindo a presença de árvores e fontes e a implantação d e equipamentos técnicos próprios a dar vazão aos mais variados fluxos - água, esgoto, gás, veículos. Formava-se uma nova sensibilidade sensorial dos pontos de vista olfativo e visual que estabelecerá sólidos liames entre as intervenções nas cidades e a noção de embelezamento, a duradoura relação entre o belo estético e a limpeza”.
Essa "ênfase na rua" na verdade não surpreende, se contemplada à luz do debate internacional sobre como a modernidade repercutiu em termos socioculturais em grandes cidades da Europa e dos Estados Unidos, seja ao longo do século XIX, seja no século XX - em dependência da concepção de modernidade que subjaz às respectivas reflexões. Uma constatação que atravessa internacionalmente as ciências sociais no mínimo desde que Walter Benjamin propôs nos anos de 1930, em relação à Paris de Baudelaire, que "a cidade pode abrir-se diante do transeunte como uma paisagem sem soleiras" é a de que a rua é não apenas um componente da modernidade nas cidades. Ela é mesmo o elemento central da modernidade e, por associação, das cidades engolfadas historicamente pelo processo. ${ }^{33}$

A cada uma das Posturas regulando o uso do espaço da rua podemos contrapor uma prática da população, que desde o período colonial exercia nas ruas, nos becos e nos largos suas estratégias de sobrevivência. ${ }^{34}$ No ano anterior ao Código de Posturas, o jornal A Província de São Paulo publicou uma reclamação sobre as quituteiras da Ladeira do Acu, posteriormente batizada Ladeira São João, importante ligação do Triângulo Histórico com a região oeste da cidade - no período anterior à construção do Viaduto do Chá. As queixas partiam do fato que essas mulheres ficavam sentadas no passeio com seus tabuleiros de fruta, e seguia reclamando da sujeira deixada pelos restos das mercadorias das quituteiras, por vezes impossibilitando a passagem, por vezes provocando acidentes de "passantes descuidados". ${ }^{35}$ As Posturas tencionavam velhos e novos embates na cidade, dialeticamente articulando repressão a antigos comportamentos e à projeção de um modelo de nova civilidade. Buscar formas de liberar a circulação nas ruas e calçadas entrelaçava uma série de temporalidades que corriam simultaneamente para os governantes e habitantes da cidade. A obsessão em descongestionar o espaço urbano, permitindo uma circulação fluída, regular, homogênea, é um dos elementos do caso das intimações sobre os passeios da rua Barão de lguape que nos mostram como há grandes disputas em aparentemente pequenas intervenções. ${ }^{36}$

\section{CONFLITOS E NEGOCIAÇÕES NOS PASSEIOS DA LIBERDADE}

Encontramos nas Obras particulares doze intimações de proprietários e/ou moradores da rua Barão de lguape no ano de 1904, todas determinando um prazo de dez dias para realização do calçamento do passeio. Podemos caracterizar, dentro das possibilidades de relação dos moradores com o poder público, três grupos de agentes acerca de sua reação às intimações. $O$ primeiro se refere à metade dos pedidos, sendo caracterizado pelo cumprimento da solicitação no prazo estabelecido pela Prefeitura, tendo a segunda visita do fiscal somente constatado a realização correta das obras - desse grupo, foram intimados 
três homens e três mulheres. ${ }^{37}$ Em outros três pedidos, o serviço se deu sem pedido de prolongamento formal do prazo, mas não no limite dado pela intimação: os três homens desse grupo protelaram o cumprimento da normativa, apenas fazendo o calçamento depois de algumas visitas do fiscal e ameaças de multa. ${ }^{38} \bigcirc$ último grupo, também composto por três homens, pediu formalmente o prolongamento do prazo dado pela Prefeitura por motivos diversos, sendo todos concedidos e os serviços sendo efetivamente realizados nos novos prazos. ${ }^{39}$

maior prolongamento de prazo deste último grupo foi solicitado por João Holl, responsável pelo lote da rua Barão de lguape, esquina com Conselheiro Furtado. ${ }^{40}$, justificando seu pedido à Prefeitura com os altos recursos necessários para execução da obra:

João Holl, proprietario, residente nasta capital, tendo sido intimado para mandar fazer calçada em frente às suas propriedades sitas à Rua Barão de lguape, desde a esquina da rua Conselheiro Furtado até o prédio da cidade Rua Barão de lguape n.57 inclusive, vem respeitosamente pedir a $V$. Exa. digne conceder um praso de seis mezes para fazer o passeio, visto tratar-se de uma area de 47 metros de cumprimento que equivalem a 141 metros quadrados de passeio, e ser bastante dispendioso o custo. ${ }^{41}$

Além do pedido de Manuel, apresentado no começo do artigo, que pede o prolongamento do prazo por noventa dias por conta da instabilidade do recente aterramento da rua, há ainda o pedido de Nicola Ferrara, morador do n 101 , que pede prorrogação de trinta dias "devido a dificuldade que tem encontrado na acquisição do material necessario". Já o proprietário do lote que compreendia os números 94, 96 e 98, Vicente Giordano, protelou a construção do calçamento evitando as visitas dos fiscais, só cumprindo a disposição depois de três visitas e ameaças de multa. Manuel Pinto, do n 140, só cumpriu a intimação depois da segunda visita, também sob ameaça do fiscal. Outro caso de protelamento foi o de Vicente Luppinari, que recebeu a intimação após ter submetido um pedido de reforma de sua casa, localizada no $n^{\circ} 146$, poucos meses antes. $\bigcirc$ particular não cumpriu o prazo, recebendo sete visitas de inspeção e uma multa, posteriormente relevada pelo fiscal Manoel G. Banik, que aparece em outros momentos da documentação do calçamento dessa rua com a mesma complacência com outros proprietários.

Como podemos ver, metade dos intimados estabeleceram táticas de negociação com a norma, não seguindo à risca a determinação do poder público, buscando formas de ajustar o cumprimento da intimação a suas necessidades. Seja agindo a partir da legalidade, seja criando estratégias para burlar a fiscalização
37. Arquivo Histórico de São Paulo (1916). Intimação a Ignez Maria das Dores. 1904. Rua Barão de Iguape, $\mathrm{n}^{\circ}$ 100. Encadernado 376; Intimação a João Baptista de Biasi. 1904. Rua Barão de Iguape, esquina com a rua Bonita, $n^{\circ}$ 62. Encadernado 376; Intimação a Joaquim Augusto de Mattos. 1904. Rua Barão de Iguape, $n^{\circ} 92$. Encadernado 376; Intimação a Maria A. da Silva. 1904. Rua Barão de Iguape, no 59. Encadernado 376; Intimação a João Baptista de Biasi. 1904. Rua Barão de Iguape, esquina com a rua Bonita, $\mathrm{n}^{\circ}$ 62. Encadernado 376; Intimação a Antonio A. Leite Penteado. 1904. Rua Barão de Iguape, esquina com a rua Bonita e rua da Fábrica. Encadernado 376; Intimação a Manuel Pinto da Silva. 1905. Rua Barão de Iguape, $\mathrm{n}^{\circ} 140$. Encadernado 403.

38. Idem. Intimação a Vicente Giordano. 1904. Rua Barão de Iguape, n 94 a 98. Encadernado 376; Intimação a Vicente Luppinari. 1905. Rua Barão de Iguape, $n^{\circ}$ 146. Encadernado 403; Intimação a Manuel Pinto da Silva. 1905. Rua Barão de Iguape, $\mathrm{n}^{\circ} 140$. Encadernado 403.

39. Idem. Intimação a Manuel Francisco Duarte. 1904. Rua Barão de Iguape, $\mathrm{n}^{\circ}$ 88. Encadernado 376; Intimação a João Holl. 1904. Rua Barão de Iguape, esquina Conselheiro Furtado até o $\mathrm{n}^{\circ} 57$. Encadernado 376; Intimação a Nicola Ferrara. 1905. Rua Barão de Iguape, $\mathrm{n}^{\circ} 101$. Encadernado 403.

40. Idem. Intimação a João Holl. 1904. Rua Barão de Iguape, esquina Conselheiro Furtado até o n 57. Encadernado 376.

41. Ibidem. 
42. O caso das intimações para a construção dos passeios dessa rua da Liberdade expõe as camadas de conflitos envolvidas nesse processo de urbanização, impedindo a pacificação da história que também é promovida por pré-determinar os lugares sociais dos diferentes agentes, ainda que parta de uma pretensa abordagem progressista da dualidade repressão (poder público) X resistência (população). Portanto, a escolha aqui recaiu sobre dimensionar essa multiplicidade de conflitos, e não produzir uma explicação a partir de uma hierarquização destes.

43. Theodoro Reichero. 1916. Rua Conselheiro Furtado, entre rua da Glória e dos Estudantes. Caixa C6/1916. Série Obras Particulares. Sub-fundo Diretoria de Obras e Viação. Fundo Prefeitura Municipal de São Paulo. Arquivo Histórico Municipal. e protelar o cumprimento notificação, os proprietários e moradores das casas da rua Barão de lguape compõem um quadro em que identificamos as maleabilidades constitutivas da legislação sobre o espaço urbano desse período. Os pedidos de perdão de multas já aplicadas são uma constante em toda a série documental Obras particulares, não só em obras que exigiam o compartilhamento de responsabilidade entre o poder público e os particulares, mas também naquelas estritamente privadas.

Os métodos de negociação e conflito no fazer da cidade atendiam a uma ampla mobilização de práticas e de conhecimentos mesmo em classes sociais distintas, como vemos não só no caso dessas intimações, mas em outros processos similares aqui relatados. Longe de construir uma imagem de equidade entre os diferentes agentes no processo de urbanização da cidade, entendemos que tal maleabilidade não era a princípio benéfica, no sentido de promover essas negociações, nem expressiva de uma debilidade do poder público. Esse caráter demonstra as potencialidades de ação dos diferentes atores, mesmo em condições díspares de força, em buscar formas dentro ou fora da norma para validar seus interesses. ${ }^{42}$

Pela documentação consultada não é possível saber se essa foi a primeira guia de passeio implementada pelo poder público nesta rua. Desde o Código de Posturas, as constantes reclamações de moradores do bairro acerca da ausência de calçamentos, guias e passeios na região nos mostram que os calçamentos eram periodicamente refeitos, com obras que por vezes se arrastavam e faziam com que trechos de ruas ficassem por longos períodos sem pavimentação. É o caso desse pedido-reclamação feito por um morador da rua Conselheiro Furtado em nome de todos os moradores do trecho localizado entra as ruas da Glória e dos Estudantes, uma década depois das intimações aqui analisadas:

Tomo a liberdade de escrever-the para não ir tômar seu precioso tempo pessoalmente, sobre assumpto que já levou a sua presença. É o pequeno trecho da rua Conselheiro Furtado entre a travessa da Glória e a rua dos Estudantes. Nesse trecho foi arrancado o antigo calçamento e feito de novo, esto há dois annos. Entretando o passeio não foi feito e o antigo não existe mais, ficou todo quebrado, por haver sido alterada a largura do passeio, devendo ter calçadas mais largas. Estamos, nós, os moradores desse trecho da rua conseTheiro furtado, obrigados a andar pelo meio da rua, pois não temos passeio, e agora, com a chuva, o antigo passeio ficou um horror para se entrar e sahir de casa. Eu ali moro, e nos dias de chuva, é um horror! Desculpe escrever-the sobre este assumpto, mas há dois annos esperamos esse melhoramento e é pequeno dispendio, visto ser um pequeno trecho da rua referida e os moradores d'essa parte prejudicada da rua, estão com esse estado angustiado [...]; um pedido o mais justo possível, após 2 anos de esperrar, n'uma rua a 5 minutos da rua 15, onde pagamos aluguel elevadíssimo. ${ }^{43}$ 
Assim, vemos um bairro contíguo à centralidade histórica da cidade com uma implementação intermitente de equipamentos de infraestrutura viária até a primeira década do século XX, mesmo em vias importantes na ligação da centralidade com os bairros mais próximos - nesse caso, a Conselheiro Furtado a conecta com o bairro contíguo do Cambuci, iniciando seu traçado próximo aos limites do Triângulo Histórico. ${ }^{44}$ As duas interpretações mais recorrentes sobre essa característica da implementação dos equipamentos viários em São Paulo nesse momento são conflitantes: em uma se exalta o trabalho constante de melhoramento das condições de urbanização necessárias ao fluxo contínuo de modificações aceleradas da cidade em modernização; a outra acusa um poder público deficiente de atender as demandas da urbanização e planejar a expansão urbana, mergulhando a cidade em uma precariedade nas áreas não centrais, em contraponto a uma cidade modernizada e bem abastecida de equipamentos na centralidade histórica. ${ }^{45}$ Acreditamos que o caso aqui abordado nos permite entender o processo de urbanização de São Paulo não por meio de seu atraso ou aceleração singular, mas sim como um vértice dos processos de modificação urbana pelo qual estavam atravessando diversas grandes cidades ocidentais no período, comportando questões fundamentais na conformação das expansões urbanas na passagem do século XIX para o século XX - especialmente quanto à simultaneidade de temporalidades no cotidiano de uma cidade e às disputas aparentes e veladas, conscientes e inconscientes, para a hegemonização de um projeto político no fazer urbano.

As táticas de resistência e negociação com o poder público por parte dos proprietários e moradores da rua Barão de lguape se relacionam com a forma com que esse equipamento urbano quase invisível, o calçamento, foi implementado na cidade. As grandes obras públicas ligadas à questão viária têm visibilidade na historiografia quando se tratam de mudanças bastante aparentes nas possibilidades de circulação. Assim, a abertura de ruas e seu calçamento só são entendidas como modificações urbanas relevantes quando inseridas em planejamentos de reestruturação da cidade, em planos urbanos ou envolvendo obras em escalas de intervenção maiores, como a construção de pontes, viadutos e largas desapropriações para a construção de grandes avenidas. ${ }^{46}$ As escalas de intervenção no entorno da antiga centralidade de São Paulo foram, no entanto, primordialmente de homogeneização da forma urbana em ocupações já existentes. ${ }^{47}$ Todavia, essas alterações eram constantes e se desenrolaram por um largo período, sendo apresentadas nos relatórios da Diretoria, durante a segunda metade do século XIX, como um melhoramento tal qual obras de vulto maior. ${ }^{48}$ Esse tipo de intervenção estava relacionado com
44. Pode-se traçar um paralelo desse caso com o exposto por Bueno (2016, p. 171-172) sobre as obras de remodelação do Vale do Anhangabaú em 1912, quando todas as edificações que ficavam compreendidas entre as ruas Libero Badaró, São João, Formosa e o Largo da Memória foram demolidas - as obras de remodelação, entretanto, só efetivamente se iniciaram três anos depois, ficando a região tomada por escombros durante todo esse período. Como se sabe, essa região estava encravada entre o Triângulo Histórico e o vetor de expansão das elites, ligando a centralidade ao Theatro Municipal, e sendo caminho para os loteamentos de Campos Elísios e Higienópolis.

45. Na primeira tradição estão os estudos clássicos sobre a urbanização de São Paulo, especialmente pautadas na tese da segunda fundação da cidade, com Paula (1954), em A segunda fundação de São Paulo; Toledo (1981), em São Paulo: três cidades em um século; uma atualização dessa perspectiva, em um estudo referencial sobre a capital paulista, é realizada por Segawa (2000) em Prelúdio da metrópole; e, como obra de referência da segunda abordagem, está consolidado o estudo de Rolnik (1997), A cidade e a lei.

46. Por isso, a constante comparação com as reformas urbanas abrangentes em países europeus - no entanto, várias das estratégias apreendidas neste estudo de caso podem ser observadas nas dinâmicas urbanas de cidades como Madri na segunda metade do século XIX. Cf. Otero Carvajal e Pallol Trigueros (2009).

47. Segawa (2000, p. 55). 
48. No levantamento feito por Bresciani (2001, p. 352, grifos da autora), calçamento, recalçamento, encanamento de águas, construção de casa de detenção, instalação de trilhos, iluminação pública, reformas e construção de edifícios públicos $\mathrm{e}$ reformas de vias apresentam-se lado a lado nos relatórios da Diretoria de Obras quando se trata dos melhoramentos realizados: "Coisas tão diferente[s] - o traçado e o calçamento das vias públicas, as redes de distribuição de energia elétrica e de água, a de coleta do esgoto e a erradicação dos cortiços - são relacionadas lado a lado com as lojas finas e as formas e dimensões das moradias ricas. Intervenções diversas justificam-se pelo lugar-comum dos preceitos sanitários; coisas heterogêneas se aproximam pela similaridade produzida pela metáfora melhoramentos construindo uma espécie de quebra-cabeça se ajustando à imagem da cidade moderna".

49. Cf. Souza (2014).

50. Várias facetas dessas disputas cotidianas são abordadas em diversas escalas por Cerasoli (2004), Ferreira (2017) e Marins (2011).

51. Engenheiro em atividade por 27 anos ininterruptos, permanecendo por nove mandatos e cinco prefeitos, nos cargos equivalentes à Diretor de Obras Públicas. Foi gestor e elaborador de planos urbanos para a capital, além de professor da Politécnica. Era um dos principais articuladores no país com as discussões transnacionais da formação do campo do urbanismo, sendo ativo em congressos e publicações internacionais.

52. Cf. Segawa (2000, p. 58102).

53. Apesar dessa linha em comum nos projetos no que aspectos estruturais da expansão urbana, o que fica expresso na definição do alinhamento e nivelamento obrigatório de todas as obras realizadas na cidade pelo Padrão Municipal. A medida visava, entre outras preocupações, evitar ou ao menos diminuir os altos custos de desapropriações para retificações posteriores de ruas ou reformas viárias de largo alcance, tal qual a reestruturação do sistema viário - que exigiria integração de ruas, abertura de avenidas e largos etc. ${ }^{49}$

Poucos anos depois dessa série de intimações e de várias outras disputas do poder público com os particulares pelo compartilhamento dos custos da urbanização da cidade, 50 os embates em torno de três planos de melhoramentos urbanos mostram a amplitude das questões abordadas até aqui. Entre $1910 \mathrm{e}$ 1911 , três propostas disputavam aprovação da Câmara para se viabilizarem como solução para as novas necessidades urbanas da capital: uma de particulares, capitaneado por Alexandre de Albuquerque; uma desenvolvida na Diretoria de Obras Municipais por seu diretor Victor da Silva Freire ${ }^{51}$ e seu vicediretor Eugenio Guilhem; e, por fim, a terceira patrocinada pelo governo estadual, de responsabilidade de Samuel das Neves. ${ }^{52}$ Todos os projetos estavam centrados em promover aberturas e alargamentos de vias, construção de viadutos, criação de praças e largos. ${ }^{53}$ Medidas, portanto, que buscavam promover uma circulação mais fluída na cidade e simultaneamente uma ação de homogeneização da forma urbana. ${ }^{54} \bigcirc$ projeto de Alexandre de Albuquerque é descartado por suscitar diversas polêmicas, como as formas de remuneração previstas no projeto e as estratégias de valorização e desvalorização de terrenos, ${ }^{55}$ enquanto as propostas de Samuel das Neves e de Freire e Guilhem são apreciadas e cotejadas pelo engenheiro francês Joseph-Antoine Bouvard a pedido da Câmara, que acaba por produzir uma quarta proposta - com muitos traços de similaridade com aquela da municipalidade. ${ }^{56}$

A proposta de Freire-Guilhem consistia em estabelecer a opção de um anel de circulação no entorno da centralidade histórica, o modelo radioconcêntrico que preservava boa parte da morfologia da área mais antiga, mas promovendo alargamentos e alinhamentos em pontos estratégicos. A opção, reforçada no plano Bouvard, foi formulada ao longo da experiência desses engenheiros, que estiveram um expressivo período a frente das ações da Diretoria de Obras. Um artigo publicado na Revista da Politécnica em 1911, em meio aos debates públicos sobre os planos, explicita a defesa de Freire da importância da promoção da circulação, demonstrando os amplos desdobramentos dessa formulação conceitual: 
Freire equaciona o problema dos Melhoramentos de São Paulo como a relação entre circulação de veículos e a trama das aglomerações, ou seja, a distribuição do espaço, em ruas, praças, habitações, logradouros, e a boa repartição do ar e da luz. Nessa relação entre espaço construído e espaço vazio, os melhoramentos dão prioridade aos fluxos e não ao espaço construído, que deve obedecer aos dispositivos técnicos da boa circulação dos fluxos de ar e sol. Melhorar é arredar obstáculos e assegurar vários fluxos em movimento, mas com arte, mantendo o centro histórico, deixando os efeitos pitorescos para a periferia, alerta. A palavra melhoramento recobre um campo de atuação no qual as noções higienistas, já incorporadas ao vocabulário técnico da engenharia, se expressam em termos de equilíbrio volumétrico numa projeção ordenada da cidade. ${ }^{57}$

A implementação parcial e paulatina dessas propostas de melhoramentos expressaram as preocupações e os embates de Freire em torno do financiamento das atividades urbanizadoras, especialmente acerca dos custos de desapropriação que viabilizassem as reformas urbanas. Depois de tantos anos à frente da Diretoria, Freire estava munido de um arsenal de legislação, repertório argumentativo e casos concretos exemplares para sustentar intervenções que seriam dispendiosas à municipalidade. Promover paulatinamente o compartilhamento dos gastos e a homogeneização das fachadas e dos alinhamentos facilitavam as reformas de maior vulto e ainda permitia usar os casos bem-sucedidos como exemplo nos debates públicos para garantir legitimidade e apoio às medidas. Em sua larga experiência, Freire entendeu que não havia condições de garantir o cumprimento de uma norma estática quanto às desapropriações, necessitando manter e renovar esse repertório para cada nova disputa que propunha novas interpretações possíveis da legislação e da jurisprudência criada. ${ }^{58}$

As questões que entrelaçam os melhoramentos urbanos e o respeito ao direito de propriedade nesse momento da urbanização das cidades ocidentais são largamente debatidos pela historiografia, indicando-nos a amplitude dos conflitos de projetos políticos que perpassam uma aparente banal construção de um passeio:

Conflicto inevitable, porque no hay reforma urbana sin batalla contra la propiedad, aunque esa reforma esté destinada a reproducir y aumentar, a corto, mediano o largo plazo, el valor de la propiedad en su conjunto, y es por eso que la propia urbanística, como cuerpo disciplinas, ha permanecido tan asociada a las posiciones del reformismo político. La batalla será más o menos limitada por la pertenencia o el respecto mayor o menor de los grupos de gestión pública al statu quo, y por los limites ideológicos, jurídicos y políticos de la sociedad en cuestión; esto es obvio. ${ }^{59}$

No caso aqui analisado, as possibilidades de negociação e disputa junto ao poder público eram ampliadas pela característica de compartilhamento de tange a circulação, as propostas ofereciam soluções distintas e inclusive conflitantes acerca de qual seria a melhor opção para direcionar fluxos na cidade. A questão da expansão urbana, por exemplo, era um ponto de divergência fundamental entre elas. Para um detalhamento das propostas dos três planos, cf. D'Elboux (2015), e para um balanço crítico de suas leituras historiográficas, cf. Jordan (2017).

54. Segundo Segawa (2000, p. 61), as prioridades para os projetos deveriam abordar "alargamento do leito e elevação do nível da rua Líbero Badaró; alargamento da rua São João, formando uma avenida, obedecendo a largura da Praça Antônio Prado; prolongamento da rua Boa Vista até o Pátio do Colégio, por meio de um viaduto; abertura de uma praça no quarteirão da rua Direita (Praça do Patriarca); prolongamento da avenida Luís Antônio até a rua Direita, entre as ruas São Bento e Líbero Badaró, e talvez até a Praça Antônio Prado”.

55. A contrapartida para o investimento do grupo representado por Albuquerque seria "desapropriar prédios e terrenos das novas vias numa faixa de cerca de 160 metros de largura, com direito de revenda ou alienação; explorar uma linha de transporte servindo $s$ avenidas e as vias adjacentes [...]; garantia de juros sobre $1 / 4$ do valor investido, estimado em 160.000:000\$000; dispensa de taxas de importação de materiais destinados as obras; além de decretos e leis da Câmara Municipal que facilitassem o empreendimento" (Ibidem, p. 73).

56. Cf. D'Elboux (2015). 
57. Bresciani (2001, p. 356, grifos nossos).

58. Um dos casos mais emblemáticos na cidade é o da desapropriação de terrenos e construções para a construção do Viaduto do Chá, discutido por Oliveira (2005).

59. Gorelik (1998, p. 117).

60. Para uma discussão sobre as escalas de observação historiográfica, cf. Fernández (2007). responsabilidades entre a população e a municipalidade na implementação da infraestrutura mais básica. Tal característica expressa as opções dos administradores públicos em sua relação com a população e com os agentes urbanizadores, criando um quadro que, enquanto permitia a realização de obras de melhoramentos reduzindo os recursos empregados, também possibilitava a disputa pelas vantagens trazidas pelos equipamentos urbanos - como já dito, não era uma disputa equânime, mas que permitia por vezes resultados não esperados. Se isso valia para os agentes urbanizadores, pequenos, médios e grandes investidores nos mercados imobiliário, de terras urbanas, aluguéis, construção etc., também era refletido nas possibilidades de interação da população nesse processo, inclusive a pauperizada. Assim, essa característica de nossa forma de urbanização propiciou que práticas da população deixassem marcas na forma da cidade e em seus usos.

As estratégias concebidas e praticadas para a implementação de melhoramentos na cidade estão intrinsecamente relacionadas a essa opção do poder público, sendo constituinte da nossa forma de urbanização. Como se vê, não se trata de uma contradição imprevista ou incapacidade dos agentes públicos de lidarem, ou projetarem, os problemas advindos do crescimento urbano. Quando falamos de opção do poder público, não afirmamos que essa era uma escolha livre, mas sim contingencial, baseada na observação dos agentes no processo de urbanização da cidade, a partir do qual se elaborou um conhecimento das formas mais ou menos efetivas na tentativa de operar uma ação de protagonismo do poder público junto às negociações e disputas pelo fazer urbano. Entendermos as imbricações políticas dessa interação entre os agentes urbanos nos foi possibilitado por partir de uma documentação fragmentária, miúda, sobre a urbanização de São Paulo. Assim, mudar a escala de observação desse processo não nos permitiu vê-lo por um ângulo diferente, mas sim apreender um elemento distinto, que não era comportado na narrativa generalizante..$^{00} \mathrm{O}$ processo de adensamento urbano dos bairros no entorno da antiga centralidade de São Paulo expressa a complexidade da disputa pelo fazer urbano na cidade. 


\section{REFERÊNCIAS}

FONTES MANUSCRITAS

Arquivo Histórico Municipal de São Paulo

OBRAS PARTICULARES. São Paulo: Fundo Prefeitura Municipal. Sub-fundo Diretoria de Obras e Viação, Caixa C6/1916, Encadernados n. 376-403. São Paulo: SMC; PMSP, 1916.

\section{LIVROS, ARTIGOS E TESES}

ANDRADE, Margarida Maria de. Bairros além Tamanduateí: o imigrante e a fábrica no Brás, Mooca e Belenzinho. Tese (Doutorado em Geografia) - Faculdade de Filosofia, Letras e Ciências Humanas, Universidade de São Paulo, São Paulo, 1991.

BRESCIANI, Maria Stela Martins. Melhoramentos entre intervenções e projetos estéticos: São Paulo (1850-1950). In: BRESCIANI, Maria Stella Martins (org.). Palavras da cidade. Porto Alegre: Editora da UFRGS, 2001. p. 343-366.

BRESCIANI, Maria Stela Martins. Cidade e história. In: OLIVEIRA, Lúcia Lippi (org.). Cidade: história e desafios. Rio de Janeiro: Editora FGV, 2002. p. 16-35.

BRESCIANI, Maria Stela Martins. A cidade e o urbano: experiências, sensibilidades, projetos. Urbana: Revista Eletrônica do Centro Interdisciplinar de Estudos sobre a Cidade, Campinas, v. 6, n. 8, p. 63-94, 2014.

BRESCIANI, Maria Stela Martins. Interdisciplinaridade? transdisciplinaridade nos estudos urbanos. Urbana: Revista Eletrônica do Centro Interdisciplinar de Estudos sobre a Cidade, Campinas, v. 7, n. 10, p. 10-62, 2015.

BRITO, Mônica Silveira. A participação da iniciativa privada na produção do espaço urbano: São Paulo, 1890-1911. 2000. Dissertação (Mestrado em Geografia) - Faculdade de Filosofia, Letras e Ciências Humanas, Universidade de São Paulo, São Paulo, 2000.

BRUNO, Ernani Silva. História e tradições da cidade de São Paulo. Rio de Janeiro: José Olympio, 1954. $3 \mathrm{v}$. 
BUENO, Beatriz Piccolotto Siqueira. A cidade como negócio: mercado imobiliário em São Paulo no século XIX. In: FRIDMAN, Fania; ABREU, Mauricio (org.). Cidades latino-americanas: um debate sobre a formação de núcleos urbanos. Rio de Janeiro: Casa da Palavra: Faperj, 2010. p. 145-165.

BUENO, Beatriz Piccolotto Siqueira. Desenho e desígnio: o Brasil dos engenheiros militares (1500-1822). São Paulo: Edusp; Fapesp, 2011.

BUENO, Beatriz Piccolotto Siqueira. Aspectos do mercado imobiliário em perspectiva histórica: São Paulo (1809-1950). São Paulo: Edusp, 2016.

CAMPOS, Cândido Malta. Os rumos da cidade: urbanismo e modernização em São Paulo. São Paulo: Editora Senac, 2002.

CAMPOS, Eudes. Arquitetura paulistana sob o Império: aspectos da formação da cultura burguesa em São Paulo. Tese (Doutorado em Arquitetura) - Faculdade de Arquitetura e Urbanismo, Universidade de São Paulo, São Paulo, 1997. 4 v.

CERASOLI, Josianne Francia. Modernização no plural: obras públicas, tensões sociais e cidadania em São Paulo na passagem do século XIX para o XX. Tese (Doutorado em História) - Instituto de Filosofia e Ciências Humanas, Universidade Estadual de Campinas, Campinas, 2004.

CERQUEIRA, Carlos Gutierrez. Tebas - vida e atuação na São Paulo Colonial. Resgate História e Arte II, 2011. Disponível em: <https://sites.google.com/site/resgatehistoriaearte/. Acesso em: 08 dez. 2018>.

CHOAY, Françoise. O urbanismo: utopias e realidades, uma antologia. São Paulo: Perspectiva, 1965.

D'ElBOUX, Roseli Maria Martins. Joseph-Antoine Bouvard no Brasil: os melhoramentos de São Paulo e a criação da Companhia City: ações interligadas. Tese (Doutorado em Arquitetura e Urbanismo) - Faculdade de Arquitetura e Urbanismo, Universidade de São Paulo, São Paulo, 2015. 2 v.

DIAS, Maria Odila Leite da Silva. Prefácio. In: PINTO, Maria Inez Machado Borges. Cotidiano e sobrevivência: a vida do trabalhador pobre na cidade de São Paulo, 1890-1914. São Paulo: Edusp, 1994. p. 1-28.

DIAS, Maria Odila Leite da Silva. Quotidiano e poder em São Paulo no século XIX. São Paulo: Brasiliense, 1995. 
ENOKIBARA, Marta. Para além do vazio: as propostas elaboradas para a Várzea do Carmo na cidade de São Paulo: séculos XIX e XX. Tese (Doutorado em Arquitetura e Urbanismo) Faculdade de Arquitetura e Urbanismo, Universidade de São Paulo, São Paulo, 2003.

FERNÁNDEZ, Sandra (comp.). Más allá del territorio: la historia regional y local como problema. discusiones, balances y proyecciones. Rosario: Prohistoria, 2007.

FERREIRA, Pedro Beresin Schleder. A avenida de mil vias: conflito, contradição e ambivalência na modernização de São Paulo (1890-1920). Dissertação (Mestrado em Arquitetura e Urbanismo) - Faculdade de Arquitetura e Urbanismo, Universidade de São Paulo, São Paulo, 2017.

FREHSE, Fraya. O tempo das ruas na São Paulo de fins do Império. São Paulo: Edusp, 2005.

FREHSE, Fraya. Ô da rua! o transeunte e o advento da modernidade em São Paulo. São Paulo: Edusp, 2011.

GORELIK, Adrián. La grilla y el parque: espacio público y cultura urbana em Buenos Aires (1887-1936). Bernal: Editora de la Universidad Nacional de Quilmes, 1998.

JORDAN, Raquel Oliveira. A cidade como questão: saberes e práticas em disputa nas propostas de "melhoramentos urbanos" para São Paulo (1890-1910). In: SIMPÓSIO NACIONAL DE HISTÓRIA, 29., Brasília, DF. Anais [...]. São Paulo: Anpuh, 2017. p. 1-15.

KUVASNEY, Eliane. Os mapas como “operadores espaciais” na construção da cidade de São Paulo do início do século XX. Revista do Instituto de Estudos Brasileiros, São Paulo, n. 64, p. 167-182, 2016.

LESSER, Jefrey. Um roteiro "brasileiríssimo" pelo bairro da Liberdade. In: CYTRYNOWICZ, Roney. Dez roteiros históricos a pé em São Paulo. São Paulo: Narrativa Um, 2007. p. 25-41.

MARINS, Paulo César Garcez. Um lugar para as elites: os Campos Elíseos de Glette e Nothmann no imaginário urbano de São Paulo. In: LANNA, Ana Lucia Duarte et al. (org.). São Paulo: os estrangeiros e a construção das cidades. São Paulo: Alameda, 2011. v. 1, p. 209-244.

NOVO, Leonardo Faggion. Entre arte e técnica: arquiteturas políticas na legitimação da profissão no Brasil (1920-1930). Dissertação (Mestrado em História) - Instituto de Filosofia e Ciências Humanas, Universidade Estadual de Campinas, Campinas, 2018.

OLIVEIRA, Maria Luiza Ferreira de. Entre a casa e o armazém: relações sociais e experiência da urbanização, São Paulo, 1850-1900. São Paulo: Alameda, 2005. 
OTERO CARVAJAL, Luis Enrique; PALLOL TRIGUEROS, Ruben. El Madrid moderno: capital de una España urbana en transformación, 1860-1931. Historia Contemporánea, Leioa, n. 39, p. 541-588, 2009.

PARETO JÚNIOR, Lindener. Pândegos, rábulas, gamelas: os construtores não-diplomados entre a engenharia e a arquitetura (1890-1960). Tese (Doutorado em Arquitetura e Urbanismo) - Faculdade de Arquitetura e Urbanismo, Universidade de São Paulo, São Paulo, 2016.

PAULA, Eurípedes Simões. A segunda fundação de São Paulo (da pequena cidade à grande metrópole de hoje). Revista de História, São Paulo, v. 8, n. 17, p. 167-179, 1954.

RIBEIRO, Vanessa Costa. Várzea do Carmo a Parque Dom Pedro II: de atributo natural e artefato: décadas de 1890 a 1950. Dissertação (Mestrado em História Social) - Faculdade de Filosofia, Letras e Ciências Humanas, Universidade de São Paulo, São Paulo, 2012.

RIBEIRO, Wagner. Tebas: o escravo arquiteto do século XVIII. Leituras da História, São Paulo, n. 50, p. $32-50,2012$.

RODRIGUES, Gustavo Partezani. Vias públicas: tipo e construção em São Paulo (1898-1945). São Paulo: Imprensa Oficial, 2010.

ROLNIK, Raquel. A cidade e a lei: legislação, política urbana e territórios na cidade de São Paulo. São Paulo: Studio Nobel, 1997.

SANTOS, Amália Cristovão dos. Em obras: os trabalhadores da cidade de São Paulo entre 1775 e 1809. Dissertação (Mestrado em Arquitetura e Urbanismo) - Faculdade de Arquitetura e Urbanismo, Universidade de São Paulo, São Paulo, 2013.

SEABRA, Odette Carvalho de Lima. Meandros dos rios nos meandros do poder Tietê e Pinheiros: valorização dos rios e das várzeas na cidade de São Paulo. Tese (Doutorado em Geografia Humana) - Faculdade de Filosofia, Letras e Ciências Humanas, Universidade de São Paulo, São Paulo, 1987.

SEGAWA, Hugo. Prelúdio da metrópole: arquitetura e urbanismo em São Paulo na passagem do século XIX ao XX. São Paulo: Ateliê Editorial, 2000.

SIMONI, Lucia Noemia. A planta da cidade de São Paulo de 1897: uma cartografia da cidade existente ou da cidade futura. In: SIMPÓSIO LUSO-BRASILEIRO DE CARTOGRAFIA HISTÓRICA, 3., 2009, Ouro Preto. Anais [...]. Belo Horizonte: UFMG, 2009. p. 1-18. 
SOUZA, José Inácio de Melo. José de Sá Rocha: engenheiro municipal: uma trajetória pessoal e a formação de um corpo técnico para gestão da cidade. Informativo Arquivo Histórico de São Paulo, São Paulo, v. 9, n. 35, 2014. Não paginado.

TOLEDO, Benedito Lima de. São Paulo: três cidades em um século. São Paulo: Duas Cidades, 1981.

Artigo apresentado em 03/04/2018. Aprovado em 15/08/2018.

\section{(cc) BY}

All the contents of this journal, except where otherwise noted, is licensed under a Creative Commons Attribution License 